\title{
Higher Education during COVID-19 Pandemic: Distance Education and Online Learning
}

\author{
Argie Anthony C. Inciso \\ argiea.inciso@lnu.edu.ph \\ Leyte Normal University, P. Paterno St., Tacloban City, 6500, Philippines
}

\begin{abstract}
In response to COVID-19 pandemic, higher education institutions implemented distance education. Online learning was adopted as the mode of delivery in instruction. With this sudden change, there were learning inequalities and barriers that occurred that affected the quality of education students received. This study is a literature review of the experiences of higher education institutions in implementing distance education through online learning during COVID-19 pandemic. The purpose of this study is to make an overview of the experiences of universities and colleges during the pandemic. Twenty-three journal articles from the Education Resources Information Center database with specific key ERIC fields in the search work were utilized and subjected to analysis. The study discussed the different challenges and issues in the implementation of distance education. Also, the struggles of students, faculty, and staff were presented.
\end{abstract}

Keywords: Higher Education; COVID-19 Pandemic; Distance Education; Online Learning

\section{Introduction}

Higher education institutions have to adapt with the emergence of COVID-19 pandemic. Without any preparation, there was a sudden change of educational framework from traditional to distance learning. Thus, it is necessary that students, faculty, and technical staff should collaborate in designing the educational framework for distance education (Mishra, Gupta, \& Shree, 2020).

There were learning inequalities and barriers during the implementation of distance learning (Murphy, 2020). Inaccessible technology, inadequate infrastructure, abrupt paradigm shift, inappropriate teacher-student ratio, unpreparedness of faculty were some of the challenges higher education institutions faced. (Dubey \& Pandey, 2020; Mishra, Gupta, \& Shree, 2020). With the uncertainty of the situation, students had negative perceptions towards online courses (Rohaman, et al., 2020). They preferred traditional than distance learning (Ince, Kabul, \& Diler, 2020). They lacked focus during online classes (Peloso, et al., 2020). According to Arora and Srinivasan (2020), there are students that are unfamiliar, unmotivated, and uncertain with virtual classes. These led to absenteeism of students and poor participation. Furthermore, students experienced anxiety and stress (Dutta, 2020). Mental health interventions should be provided to faculty and students (Mishra, Gupta, \& Shree, 2020). Also, some students experienced difficulty in accessing distance education resources due to the unavailable internet connection in their respective areas (Dutta, 2020; Ince, Kabul, \& Diler, 2020; Mishra, Gupta, \& Shree, 2020). It is important that ICT facilities be readily accessible to faculty and students (Dubey \& Pandey, 2020; Mishra, Gupta, \& Shree, 2020).Thus, institutions should provide instructional support to all students by addressing the challenges they encountered in their respective setting (Mishra, Gupta, \& Shree, 
2020). The use of different strategies in providing education should be done to address these concerns. In addition, findings also show that faculty struggle in using technology (Ifran, et al., 2020; Peloso, et al., 2020). Learning management systems were used for online classes. However, it still needs improvement in software capabilities that will support the different online courses (Ifran, et al., 2020). The use of social media was a great help in maintaining communication between students and teachers (Al-Youbi, et al., 2020; Dutta, 2020; Mishra, Gupta, \& Shree, 2020). Indeed, it is important that institutions should conduct faculty and student trainings in using technology for their online classes (Dubey \& Pandey, 2020; Mishra, Gupta, \& Shree, 2020; Peloso, 2020).

This study aims to discuss the challenges and issues of higher education institutions with the COVID19 pandemic by analyzing existing publications in 2020. This is to make an overview on the experiences of different universities and colleges during the pandemic.

\section{Methodology}

This is a literature review focused on the findings of published journal articles on higher education during COVID-19 pandemic. This study utilized journal articles found in the Education Resources Information Center database which is sponsored by the Institute of Education Sciences of the United States Department of Education.

Table 1. Set of key ERIC fields in the search work.

\begin{tabular}{ll}
\hline Publication Date & 2020 \\
\hline Descriptors & $\begin{array}{l}\text { COVID-19, Pandemics, Distance Education, School Closing, } \\
\text { Online Courses, Higher Education }\end{array}$ \\
\hline Publication Type & Journal Articles \\
\hline Educational Level & Higher Education \\
\hline
\end{tabular}

Journal articles published on 2020 about higher education during COVID-19 pandemic were utilized. Twenty-three (23) studies were systematically analyzed to gather meaningful data.

Table 2. Frequency of studies based on design

\begin{tabular}{ll}
\hline Qualitative & 6 \\
\hline Quantitative & 4 \\
\hline Mixed Methods & 3 \\
\hline Narrative & 5 \\
\hline Documentary & 1 \\
\hline Commentary & 4 \\
\hline
\end{tabular}

The studies have different research methodologies. The qualitative studies (6) mainly focused on lived experiences of faculty and students during the implementation of distance learning. Narrative researches' (5) subject of interest were on their lived experiences as well but by telling their stories. Online surveys were conducted for quantitative studies (4). Important viewpoints and insights were discussed in research commentaries (4). For mixed methods (3), online survey and interview was done not to triangulate but to use the data in analyzing their situations. Lastly, the use of existing evidences like documents and reports were 
utilized in the documentary research (1).

Table 3. Frequency of studies based on subject of interest

\begin{tabular}{ll}
\hline Faculty & 4 \\
\hline Students & 5 \\
\hline Literature & 3 \\
\hline Faculty and Staff & 3 \\
\hline Faculty and Students & 8 \\
\hline
\end{tabular}

The focus of interest of the different studies were on students, faculty, staff, and existing literatures that would give meaningful data for their conduct of study. Research findings were utilized for data analysis and as a basis for discussion on this literature review.

\section{Results and Discussion}

\subsection{Education Framework and COVID-19 Pandemic}

Higher education institutions should reflect on COVID-19 pandemic experiences- sudden closure of campuses, transition from traditional to remote learning, economic consequences, and uncertain educational plans- in constructing education frameworks (Bolumole, 2020). However, educational sectors did not only encounter the challenges of COVID-19 pandemic but also natural calamities (Brisbon III, Lovett, \& Griggs, 2020). It is important that online learning should be planned carefully to achieve meaningful results (AlShamsi, Mohaidat, Al Hinai, \& Samy, 2020; Anstey, et al., 2020; Daniel, 2020; Johnson, Veletsianos, \& Seaman, 2020; Ochavillo, 2020; Parnia, 2020; Pham \& Ho, 2020; Quezada \& Quezada-Parker, 2020). Long-term solutions should be considered in the delivery of instruction to students (Johnson, Veletsianos, \& Seaman, 2020). But a prompt response by providing accessible, efficient provisional learning support is necessary rather than creating a new educational framework to address immediately the current situation (Nissim \& Simon, 2020; PrataLinhares, Cardoso, Lopes-Jr, \& Zukowsky-Tavares, 2020). Thus, engaging students in making the curriculum framework is necessary (Bryson \& Andres, 2020). And, planning should include the community and stakeholders as well to address future challenges (Parnia, 2020).

\subsection{Distance Education and Online Learning}

Institutions should use variety of methods in instruction for student engagement and assessment procedure in online learning (Ożadowicz, 2020; Schweiker \& Levonis, 2020). But parents, students, and faculty were not ready (Ochavillo, 2020; Prata-Linhares, Cardoso, Lopes-Jr, \& Zukowsky-Tavares, 2020). Parents were having financial difficulties in supporting their children (Ochavillo, 2020). Thus, financial assistance program for students would help cater the demands of online learning (Brisbon III, Lovett, \& Griggs, 2020). Furthermore, online learning support should be given to students, faculty, and staff (Ali, 2020; Alqahtani \& Rajkhan, 2020; AlShamsi, Mohaidat, Al Hinai, \& Samy, 2020; Brisbon III, Lovett, \& Griggs, 2020; Daniel, 2020; Johnson, Veletsianos, \& Seaman, 2020; Moluayonge, 2020; Quezada \& Quezada-Parker, 2020; Richardson, 2020). It should be noted that faculty capability, interventions, student perceptions, and technological skills affect the delivery of online learning (Alqahtani \& Rajkhan, 2020). ICT infrastructures and tools should be readily available to faculty and students (Ali, 2020; AlShamsi, Mohaidat, Al Hinai, \& Samy, 2020; Johnson, Veletsianos, \& Seaman, 2020; Moluayonge, 2020; Prata-Linhares, Cardoso, Lopes-Jr, \& Zukowsky-Tavares, 2020; Ożadowicz, 2020). Alternative assessment strategies should be used in response to the different challenges encountered by students (Osman, 2020; Quezada \& Quezada-Parker, 2020). And teachers should be 
equipped with the necessary technological skills (Daniel, 2020; Johnson, Veletsianos, \& Seaman, 2020; Pham \& Ho, 2020; Osman, 2020). It is because students were more technologically inclined than them (Osman, 2020). Furthermore, successful academic performance needs positive outlook, dedication, and motivation from students (Alqahtani \& Rajkhan, 2020; Anstey, et al., 2020; Osman, 2020). However, students experienced anxiety and stress (Ghazi-Saidi, et al., 2020). They were also unmotivated (Ghazi-Saidi, et al., 2020). Accordingly, uncertainty and stress affects students' perceptions towards distance learning (Ghazi-Saidi, et al., 2020; Nissim \& Simon, 2020). This includes the availability of vaccine and stability of socio-economy (AlShamsi, Mohaidat, Al Hinai, \& Samy, 2020). Students were not satisfied with the change of delivery in instruction (Ghazi-Saidi, et al., 2020). But it changed positively after how many weeks (AlShamsi, Mohaidat, Al Hinai, \& Samy, 2020). Interventions were made to relieve anxiety and stress to students and teachers (Johnson, Veletsianos, \& Seaman, 2020; Quezada \& Quezada-Parker, 2020). Even though faculty experienced anxiety and stress, they still supported students to ease such feelings (Ghazi-Saidi, et al., 2020; Johnson, Veletsianos, \& Seaman, 2020). Also, active participation in flexible and efficient online learning activities reduces stress among students (Anstey, et al., 2020). Students preferred traditional than online learning (AlShamsi, Mohaidat, Al Hinai, \& Samy, 2020; Brisbon III, Lovett, \& Griggs, 2020; Osman, 2020; Ritonga, et al., 2020). With the lack of technology, students experienced difficulties (Ghazi-Saidi, et al., 2020). Also, their familiarity of distance learning affected their performance (AlShamsi, Mohaidat, Al Hinai, \& Samy, 2020; Ghazi-Saidi, et al., 2020; Parnia, 2020). Indeed, technology innovations should be an area of interest for research to improve instruction (AlShamsi, Mohaidat, Al Hinai, \& Samy, 2020; Ożadowicz, 2020). Educational institutions should collaborate in research and technical trainings to address learning inequalities. (Brisbon III, Lovett, \& Griggs, 2020; Daniel, 2020; Osman, 2020; Prata-Linhares, Cardoso, Lopes-Jr, \& Zukowsky-Tavares, 2020)

\subsection{Pedagogical Strategies}

Online learning experiences should be extensive and intensive (Bryson \& Andres, 2020). Student collaboration, discussion forums, interactive hypermedia, use of flexible synchronous and asynchronous sessions are pedagogical strategies of an effective online learning set up (Moluayonge, 2020). Synchronous and asynchronous sessions were used in online classes (Quezada \& Quezada-Parker, 2020). Students found asynchronous videos more convenient than having text-based discussions. It provides greater student participation. Some students preferred searching in the internet and using technology in learning than teacher discussions (Ritonga, et al., 2020). It lessens student pressure compared to live discussions and is flexible to different situations (Ghazi-Saidi, et al., 2020). However, communication between teacher and students was more evident in synchronous than in asynchronous discussions (Lowenthal, Borup, West, \& Archambault, 2020). Also, asynchronous activities were beneficial to working students (Ghazi-Saidi, et al., 2020). Online learning can provide an individualized learning experience to students (Ghazi-Saidi, et al., 2020). Online resources like learning modules (Bryson \& Andres, 2020), social media (Ritonga, et al., 2020; Richardson, 2020; Bryson \& Andres, 2020), and learning management systems- Google classroom, Google Meet, Google Docs, and other Google products (Moluayonge, 2020)- were utilized to promote active participation from students. Interestingly, students preferred blended learning as the mode of delivery in instruction (Ożadowicz, 2020; Pham \& Ho, 2020).

\section{Conclusions}

Higher education institutions experienced different challenges in the implementation of education during COVID-19 pandemic. Online learning platforms were introduced to faculty and students to cater the demands of the new normal in education. This sudden change from traditional to distance education brought concerns as to the effectivity of the method. It is necessary that higher education institutions should meet the demands of online learning to eliminate barriers and inequalities in distance education. Research and technology 
innovations should be done to address these situations.

\section{Recommendations}

This study is limited to journal articles published on 2020 that are found in Education Resources Information Center database with specific set of key ERIC fields in the search work. Thus, the use of journal articles aside from the database will give a more comprehensive understanding to the experiences of higher education institutions during COVID-19 pandemic. Also, the researcher is aware that the studies were conducted from different countries with different struggles during COVID-19 pandemic. With this, geographical representations should be considered to improve future studies.

\section{References}

Alqahtani, A. Y., \& Rajkhan, A. A. (2020). E-learning critical success factors during the covid-19 pandemic: A comprehensive analysis of e-learning managerial perspectives. Education Sciences, 10(9), 216.

Ali, W. (2020). Online and remote learning in higher education institutes: A necessity in light of COVID-19 pandemic. Higher Education Studies, 10(3), 16-25.

AlShamsi, A., Mohaidat, J., Al Hinai, N., \& Samy, A. (2020). Instructional and Business Continuity Amid and Beyond COVID-19 Outbreak: A Case Study from the Higher Colleges of Technology. International Journal of Higher Education, 9(6), 118-135.

AI-Youbi, A. O., Al-Hayani, A., Bardesi, H. J., Basheri, M., Lytras, M. D., \& Aljohani, N. R. (2020). The King Abdulaziz University (KAU) pandemic framework: A methodological approach to leverage social media for the sustainable management of higher education in crisis. Sustainability, 12(11), 4367.

Anstey, M. R., Blauch, D. N., Carroll, F. A., Gorensek-Benitez, A. H., Hauser, C. D., Key, H. M., Myers, J. K., Stevens, E. P., Striplin, D. R., Holck, H. W., Montero-Lopez, L., \& Snyder, N. L. (2020). \# DavidsonTrue: Transitioning to Remote Teaching while Maintaining Our Values as a Liberal Arts College during the COVID-19 Pandemic. Journal of Chemical Education, 97(9), 2800-2805.

Arora, A. K., \& Srinivasan, R. (2020). Impact of pandemic COVID-19 on the teaching-learning process: A study of higher education teachers. Prabandhan: Indian journal of management, 13(4), 43-56.

Bolumole, M. (2020). Student life in the age of COVID-19. Higher Education Research \& Development, 39(7), 1357-1361.

Brisbon III, R. H. A., Lovett, H. I., \& Griggs, E. D. (2020). Higher Education in New Orleans Post Hurricane Katrina through COVID19. About Campus, 25(3), 5-7.

Bryson, J. R., \& Andres, L. (2020). Covid-19 and rapid adoption and improvisation of online teaching: curating resources for extensive versus intensive online learning experiences. Journal of Geography in Higher Education, 44(4), 608-623.

Daniel, J. (2020). Covid-19-A Two-Week Transition from Campus to Online at the Acsenda School of Management, Canada. Journal of Learning for Development, 7(3), 271-285.

Dubey, P., \& Pandey, D. (2020). Distance learning in higher education during pandemic: challenges and opportunities. The International Journal of Indian Psychology, 8(2), 43-46.

Dutta, A. (2020). Impact of digital social media on Indian higher education: alternative approaches of online learning during COVID-19 pandemic crisis. International journal of scientific and research publications, 10(5), 604-6011.

Ghazi-Saidi, L., Criffield, A., Kracl, C. L., McKelvey, M., Obasi, S. N., \& Vu, P. (2020). Moving from face-to-face to remote instruction in a higher education institution during a pandemic: Multiple case studies. International Journal of Technology in Education and Science, 4(4), 370-383.

İnce, E. Y., Kabul, A., \& Diler, İ. (2020). Distance education in higher education in the COVID-19 pandemic process: A case of Isparta Applied Sciences University. Distance Education, 4(4).

Irfan, M., Kusumaningrum, B., Yulia, Y., \& Widodo, S. A. (2020). Challenges during the pandemic: use of e-learning in mathematics learning in higher education. Infinity Journal, 9(2), 147-158.

Johnson, N., Veletsianos, G., \& Seaman, J. (2020). US Faculty and Administrators' Experiences and Approaches in the Early Weeks of the COVID-19 Pandemic. Online Learning, 24(2), 6-21.

Lowenthal, P., Borup, J., West, R., \& Archambault, L. (2020). Thinking beyond Zoom: Using asynchronous video to maintain connection and engagement during the COVID-19 pandemic. Journal of Technology and Teacher Education, 28(2), 383-391.

Mishra, L., Gupta, T., \& Shree, A. (2020). Online teaching-learning in higher education during lockdown period of COVID-19 pandemic. International Journal of Educational Research Open, 1, 100012.

Moluayonge, G. (2020). The Use of Modern Educational Technologies in Remote Learning in Higher Education During a Pandemic: the Case of COVID-19 in Cameroon. Journal of Learning for Development, 7(3), 479-484.

Murphy, M. P. (2020). COVID-19 and emergency eLearning: Consequences of the securitization of higher education for post-pandemic pedagogy. Contemporary Security Policy, 41(3), 492-505

Nissim, Y., \& Simon, E. (2020). Agility in Teacher Training: Distance Learning During the Covid-19 Pandemic. International Education Studies, 13(12), 11-25 
Ochavillo, G. S. (2020). A Paradigm Shift of Learning in Maritime Education amidst COVID-19 Pandemic. International Journal of Higher Education, 9(6), 164-177.

Osman, M. E. (2020). Global impact of COVID-19 on education systems: the emergency remote teaching at Sultan Qaboos University. Journal of Education for Teaching, 46(4), 463-471.

Ożadowicz, A. (2020). Modified Blended Learning in Engineering Higher Education during the COVID-19 Lockdown-Building Automation Courses Case Study. Education Sciences, 10(10), 292.

Parnia, A. (2020). As COVID-19 Batters Higher Education, A Proposal to Move Online Fast. New England Journal of Higher Education.

Peloso, R. M., Ferruzzi, F., Mori, A. A., Camacho, D. P., Franzin, L. C. D. S., Margioto Teston, A. P., \& Freitas, K. M. S. (2020). Notes from the field: concerns of health-related higher education students in Brazil pertaining to distance learning during the coronavirus pandemic. Evaluation \& the Health Professions, 43(3), 201-203.

Pham, H. H., \& Ho, T. T. H. (2020). Toward a 'new normal'with e-learning in Vietnamese higher education during the post COVID-19 pandemic. Higher Education Research \& Development, 39(7), 1327-1331.

Prata-Linhares, M. M., Cardoso, T. D. S. G., Lopes-Jr, D. S., \& Zukowsky-Tavares, C. (2020). Social distancing effects on the teaching systems and teacher education programmes in Brazil: reinventing without distorting teaching. Journal of Education for Teaching, 46(4), 554-564.

Quezada, R. L., Talbot, C., \& Quezada-Parker, K. B. (2020). From Bricks and Mortar to Remote Teaching: A Teacher Education Program's Response to COVID-19. Journal of Education for Teaching, 46(4), 472-483.

Richardson, M. E. (2020). Social Media in the Classroom. The New Normal for University Education after COVID. International Dialogues on Education: Past and Present, 7, 14-18.

Ritonga, A.W., Ritonga, M., Nurdianto, T., Kustati, M., Rehani, Lahmi, A., Yasmadi, Pahri (2020). E-learning process of maharah qira'ah in higher education during the covid-19 pandemic. International Journal of Higher Education, 9(6), 227-235.

Rohman, M., Marji, D. A. S., Sugandi, R. M., \& Nurhadi, D. (2020). Online learning in higher education during covid-19 pandemic: students' perceptions. Journal of Talent Development and Excellence, 12(2s), 3644-3651.

Schweiker, S. S., \& Levonis, S. M. (2020). Insights Gained While Teaching First Semester Chemistry in the Time of COVID-19 at Bond University in Australia. Journal of Chemical Education, 97(9), 2863-2865. 